\title{
Versatile Dual-Inlet Sample Introduction System for Multi- Mode Single Particle Inductively Coupled Plasma Mass Spectrometry Analysis and Validation
}

\author{
Daniel Rosenkranz ${ }^{1}$, Fabian L. Kriegel ${ }^{1}$, Emmanouil Mavrakis ${ }^{2}$, Spiros A. Pergantis ${ }^{2}$, Philipp Reichardt ${ }^{1}$, Jutta \\ Tentschert ${ }^{1}$, Norbert Jakubowski ${ }^{4}$, Peter Laux ${ }^{1}$, Ulrich Panne ${ }^{3}$, Andreas Luch ${ }^{1}$ \\ ${ }^{1}$ Department of Chemical and Product Safety, German Federal Institute for Risk Assessment (BfR) ${ }^{2}$ Environmental Chemical Processes Laboratory, \\ Department of Chemistry, University of Crete ${ }^{3}$ Federal Institute for Materials Research and Testing (BAM) ${ }^{4}$ SPETEC GmbH
}

\section{Corresponding Author}

Daniel Rosenkranz

daniel.rosenkranz@bfr.bund.de

\section{Citation}

Rosenkranz, D., Kriegel, F.L.,

Mavrakis, E., Pergantis, S.A.,

Reichardt, P., Tentschert, J.,

Jakubowski, N., Laux, P., Panne, U.,

Luch, A. Versatile Dual-Inlet Sample

Introduction System for Multi-Mode

Single Particle Inductively Coupled

Plasma Mass Spectrometry Analysis and

Validation. J. Vis. Exp. (163), e61653,

doi:10.3791/61653 (2020).

\section{Date Published}

September 24, 2020

DOI

$10.3791 / 61653$

URL

jove.com/video/61653

\section{Abstract}

Metal-containing nanoparticles (NP) can be characterized with inductively coupled plasma mass spectrometers (ICP-MS) in terms of their size and number concentration by using the single-particle mode of the instrument (spICP-MS). The accuracy of measurement depends on the setup, operational conditions of the instrument and specific parameters that are set by the user. The transport efficiency of the ICP-MS is crucial for the quantification of the NP and usually requires a reference material with homogenous size distribution and a known particle number concentration.

Currently, NP reference materials are available for only a few metals and in limited sizes. If particles are characterized without a reference standard, the results of both size and particle number may be biased. Therefore, a dual-inlet setup for characterizing nanoparticles with spICP-MS was developed to overcome this problem. This setup is based on a conventional introduction system consisting of a pneumatic nebulizer (PN) for nanoparticle solutions and a microdroplet generator $(\mu \mathrm{DG})$ for ionic calibration solutions. A new and flexible interface was developed to facilitate the coupling of $\mu \mathrm{DG}, \mathrm{PN}$ and the ICP-MS system. The interface consists of available laboratory components and allows for the calibration, nanoparticle (NP) characterization and cleaning of the arrangement, while the ICP-MS instrument is still running.

Three independent analysis modes are available for determining particle size and number concentration. Each mode is based on a different calibration principle. While mode I (counting) and mode III ( $\mu \mathrm{DG})$ are known from the literature, mode II (sensitivity), is used to determine the transport efficiency by inorganic ionic standard solutions only. It is independent of NP reference materials. The $\mu \mathrm{DG}$ based inlet 
system described here guarantees superior analyte sensitivities and, therefore, lower detection limits (LOD). The size dependent LODs achieved are less than $15 \mathrm{~nm}$ for all NP ( $\left.\mathrm{Au}, \mathrm{Ag}, \mathrm{CeO}_{2}\right)$ investigated.

\section{Introduction}

Inductively coupled plasma mass spectrometers are extensively used to quantify size and number of NP in various samples and matrices in the so called single particle mode $^{1,2,3}$. The single particle mode is an operation of the data acquisition system with a short integration or dwell time. Each NP measured produces an integrated signal in this time interval (event measured in counts per second: $c p s$ ) if an adequate dilution of the NP suspension was used to avoid double events. Calibration standard, as well as the sample, are usually introduced into the ICP-MS via a conventional sample introduction system based on pneumatic nebulization $(\mathrm{PN})^{4}$. However, as a prerequisite, the sample introduction flow rate and transport efficiency $(\eta)$ must be determined to accurately quantify the metal mass per NP and to determine their number concentration in the suspension. The transport efficiency describes the ratio of the mass or particle number injected to the mass (waste collecting method)) or particle number (counting method) detected by the ICP-MS ${ }^{5}$. The transport efficiency is most frequently determined using nanoparticle-based reference materials ${ }^{5}$. However, transport properties depend on the structure of the NP, and involves properties like composition and sample dispersant. Other influencing factors are instrumental parameters, like sample uptake rate, nebulizer gas flow rate, dwell time and total measurement time.

Since only limited nanoparticulate reference materials are available, the obtained NP analysis results can be biased due to differences in elemental composition between reference and sample particles. Besides the availability of a limited range of reference materials, the detection of multiple particle events per detector dwell time represents a further challenge. This may also affect the accuracy of the transport efficiency to be determined.

To be independent of reference materials, ideally, a sample introduction system with a transport efficiency of almost $100 \%$ is preferable. At the same time when a low volume is used compared to conventional introduction systems, higher particle number concentrations can be used. Even if two particles are close to each other both can be separately detected with the $\mu \mathrm{DG}$ based system.

The $\mu D G$ is able to generate monodisperse droplets with a fixed volume in the $\mathrm{pL}$ range and is well-suited for this purpose $6,7,8,9$. The $\mu \mathrm{DG}$ facilitates the injection of both ionic and particulate samples in different solvents into the ICP-MS. In case of ionic metal samples, it is assumed that the droplets generated are fully desolvated on the way to the ICP. Accordingly, the droplet loses all water and a particle is formed from the remaining salt. The diameter of this particle is directly proportional to the concentration used. Thus, homemade reference standards of the same matrix, mass, and size, with varying concentration of the ionic solution of the NP to be investigated, can be produced in-house. The volume of a droplet can be calculated easily based on the droplet diameter measured by the $\mu D G$. This is not possible with a $P N$ which produces a wide distribution of droplets with different diameters ${ }^{10,11}$. Due to the uniform sample introduction at 
high transport efficiency of $100 \%$ of the $\mu \mathrm{DG}$, high instrumentspecific analyte sensitivity can be achieved. Depending on the matrix used, this leads to lower limits of detection (LOD) of particle mass and size when compared to the results of conventional introduction systems based on $\mathrm{PN}^{12}$. However, due to the design of the $\mu D G$, samples cannot be exchanged easily when the ICP-MS system is still operating. Between measurements of different samples, the $\mu D G$ has to be cleaned and afterwards flushed with the sample solution for system stabilization. In addition, its tolerance to heavy matrix samples has not been tested to great extent. Moreover, due to the extremely low flow rates, the analysis time to achieve good statistics would be extremely long, which limits its practical use, if "real" samples, as for instance environmental waters, should be analyzed.

To overcome these limitations, the $\mu \mathrm{DG}$ has been previously operated in combination with a conventional pneumatic nebulizer based system, which was given the name of a dual inlet system ${ }^{13}$. By introducing the calibration standards with the $\mu \mathrm{DG}$ and the NP suspension via a pneumatic nebulizer into the ICP-MS, Ramkorun-Schmidt et al. were able to take advantage of both systems ${ }^{13}$. Highly accurate determination of the metal mass fraction of $\mathrm{Au}$ and $\mathrm{Ag}$ NP were achieved, without a need for transport efficiency determination. However, no particle number concentrations were determined with this dual inlet system. Also, cleaning and alignment of the $\mu D G$ system was complicating the applicability for routine analysis.

In this paper, we propose a flexible dual inlet interface for determining NP particle size and particle number concentration and demonstrate the assembly and practical use of it. Like the system of Ramkorun-Schmidt et al. it consists of both an $\mu \mathrm{DG}$ as well as $\mathrm{PN}$ sample introduction system. We demonstrate that the dual-inlet system, in its present stage of development, allows the application of three independent modes of analysis to investigate and characterize metal-containing NPs. Our dual-inlet system simplifies the calibration procedure for NP determination and improves the analytical figures of merit in particular the accuracy ${ }^{14}$. The inlet systems allow convenient sample exchange and cleaning of the $\mu \mathrm{DG}$ even when the ICP-MS is still operating, thereby reducing the overall analysis time and the risk of misalignment. In order to test the system performance well characterized reference NP (60 nm AuNP - NIST 8013, 75 nm AgNP - NIST 8017) are used for method validation and comparability.

\section{Protocol}

\section{Assembly of the dual-inlet sample introduction setup}

NOTE: Details about different parts are shown in Table 1.

\begin{tabular}{|c|c|}
\hline \multirow{2}{*}{ Part 1 } & Components \\
\hline & Glass female spherical ball joint with approximately $10 \mathrm{~mm}$ shank length \\
\cline { 2 - 3 } & Glass male ball joint with approximately $10 \mathrm{~mm}$ shank length \\
\cline { 2 - 3 } & Metal T-piece (dimensions: $1 / 4 \mathrm{in})$ \\
\cline { 2 - 3 } & Glass to metal adhesive \\
\hline
\end{tabular}




\begin{tabular}{|c|c|}
\hline \multirow{2}{*}{ Part 2 } & $\begin{array}{c}\text { ICP-MS spray chamber (suggested type: impact bead } \\
\text { spray chamber, cyclonic spray chamber or similar) }\end{array}$ \\
\cline { 2 - 3 } & Pneumatic nebulizer (suggested type: concentric nebulizer) \\
\cline { 2 - 3 } & Clamp \\
\cline { 2 - 3 } & O-ring free quartz torch \\
\cline { 2 - 3 } & Gas line connector closed-end \\
\cline { 2 - 3 } & Gas line connector open-end \\
\hline Part 4 & Conductive and flexible silicone tube \\
\hline Part 5 & Piezoelectric Micro droplet generation unit \\
\hline
\end{tabular}

Table 1: List of Components used to build up the dual-inlet setup.

1. Construction of a T-piece connector unit (Figure 1 Part 1).

NOTE: This part connects the conventional sample introduction system (step 1.2) and the $\mu \mathrm{DG}$ transport unit (step 1.3).

1. Insert a male and female ball joints to the opposite openings of a T-piece connector.

2. Secure the male and female ball joints by using a glass to metal adhesive (e.g., silicon glue).

3. Connect the female ball joint to the injector of the ICPMS using a clamp.

2. Attachment of a conventional sample introduction system (Figure 1 Part 2)

NOTE: This part is connected to the T-piece connector unit (step 1.1)

1. Combine an ICP-MS spray chamber with a pneumatic nebulizer (PN), which fits into the spray chamber being used.
2. Use a clamp to connect the spray chamber outlet to the male ball joint of the T-piece connector (described in step 1.1).

NOTE: The spray chamber outlet is usually equipped with a female ball joint connector. The combination shown in Figure 1 consists of a nebulizer and an impact bead spray chamber. Instead of the impact bead spray chamber other spray chambers with transport efficiencies in range of 2 to $10 \%$ or higher can be used.

3. Construction of the microdroplet transport unit (Figure 1 Part 3)

NOTE: This part connects the T-piece connector unit (step 1.1) and the $\mu D G$ unit (step 1.4).

1. Attach a demountable quartz torch, with its injector tube removed, to a laboratory stand with the torch inlet on the top using appropriate clamps.

2. Block the torch plasma/auxiliary gas inlet by closed end gas connectors. 
NOTE: The sample is transported using a peristaltic pump to the nebulizer. Argon gas is used for sample nebulization into the spray chamber and further transportation into the plasma.

3. Connect a helium gas line to the torch via its cooling gas inlet by using an appropriate gas connector.

NOTE: The applied helium gas is used for the desolvation of generated droplets and act as a sheath gas preventing the droplet from a collision with the walls of the setup and in preventing the ICP-MS instrument from atmospheric oxygen insertion while the sample inlet head of the $\mu \mathrm{DG}$ has to be removed for cleaning and sample exchange.

4. Connect a $30 \mathrm{~cm}$ long conductive and flexible silicone tube (i.d. $0.75 \mathrm{~cm}$ ), using an adapter, to the exit end of the torch (bottom of torch).

5. Connect the downward end of the silicone tubing to the T-piece connector unit by stretching the flexible silicone tubing over its remaining vertical metal connection.

NOTE: The flexible silicone tubing allows $x-y-z$ tuning of the ICP-MS instrument with the connected setup.

4. Connection of the microdroplet generation unit and microdroplet generation control unit (Figure 1 Part 4, Part

5)

NOTE: This part is connected to the $\mu \mathrm{DG}$ transport unit (step 1.3)

1. Connect the prepared $\mu \mathrm{DG}$ unit to the microdroplet transport unit by inserting the $\mu \mathrm{DG}$ head into the sample inlet end of the torch.

2. Connect the power supply to the $\mu D G$ control unit.

NOTE: The setup described here consists of a commercially available $\mu \mathrm{DG}$ head and $\mu \mathrm{DG}$ power supply. Depending on $\mu \mathrm{DG}$ head used the setup must be adapted accordingly.

\section{Quantification of droplet size}

1. Use a stroboscope light and a CCD camera (e.g., in an open configuration, see Figure 1 size measurement configuration) for taking images of produced droplets by the $\mu \mathrm{DG}$.

2. Calibrate the CCD camera by taking images of an object of known size in $\mu \mathrm{m}$ range (e.g., copper wire with a diameter of $150 \mu \mathrm{m})$.

3. Take images of at least 1,000 drops at the settings used for the experiment (see Table 2).

4. Use an appropriate graphical software program (see Table of Materials) to evaluate the images concerning the object and drop size in the following steps:

1. Click File and Open to load the image of the object.

2. Click Image | Adjust | Threshold to define the area of the object by moving the scroll bars.

3. Click Apply to apply the settings.

4. Click on the Straight segment button.

5. Click and hold the left mouse button to draw a line alongside the object.

6. Press $\mathbf{C t r l}+\mathbf{M}$ to measure the object size.

7. Measure the diameter of the object at 5 different points.

8. Copy and Paste the "Results" table in a spreadsheet software.

9. Calculate the arithmetic mean of the column "Length". 
10. Calculate the pixel aspect ratio (PAR): actual object size $(\mu \mathrm{m}) /$ mean object size in the image $(p x)$.

11. Click File | Import | Image Sequence to import and load the images of the droplets.

12. Click Rectangular and mark the droplet of the first image.

13. Perform the right click on the mouse pad and choose Duplicate to separate the droplets of the image sequence from the rest of the image.

14. Separate the droplets from the background as specified in step 2.4.2.

15. Click Process | Binary | Erode to remove reflections of light on the droplet surface.

16. Click Process | Binary | Dilate to reverse the "Erode" step.

17. Click Analyze | Analyze Particles | Ok to measure all droplets.

18. Copy and Paste the "Summary" or "Result" table into a spreadsheet software.

19. Calculate the arithmetic mean of the ferret diameter in $\mathrm{px}$.

20. Use the PAR to transform the diameter in $\mu \mathrm{m}$ : ferret diameter in px/PAR.

NOTE: The size of the droplets formed by the $\mu \mathrm{DG}$ varies depending on the selected length and duration of the current pulse applied to the piezo element ${ }^{7}$.

\section{Sample preparation}

1. Prepare an ionic calibration solution of the analyte to be measured in the concentration range of 0.2 to $20 \mu \mathrm{g} / \mathrm{L}$ in dilute acid (e.g., $\left.\mathrm{HCl}(0.5 \mathrm{v} / \mathrm{v}), \mathrm{HNO}_{3}(3.5 \mathrm{v} / \mathrm{v})\right)$.
2. Prepare an ionic solution for the one-point calibration in the concentration range between 1 and $10 \mu \mathrm{g} / \mathrm{L}$ in dilute acid.

3. Prepare the NP standard suspensions according to the manufacturer's instructions or in-house protocols.

NOTE: Steps 3.3.1 - 3.3.4 explain the preparation of the NP standard suspensions considering $\mathrm{Ag}, \mathrm{Au}, \mathrm{CeO}_{2} \mathrm{NPs}$ as example.

1. Prepare $10 \mathrm{~mL}$ of $0.05 \mu \mathrm{g} / \mathrm{L}$ AuNP solution for the $P N$ and $1 \mu \mathrm{g} / \mathrm{L}$ AuNP solution in ultrapure water for $\mu \mathrm{DG}$. Vortex for 20-60s before using.

2. Prepare $0.05 \mu \mathrm{g} / \mathrm{L}$ AgNP solution for the $P N$ and 2 $\mu g / L$ AgNP solution, both in ultrapure water, for $\mu \mathrm{DG}$. Shake well for $20-60$ s before using ${ }^{15}$.

3. Prepare $\mathrm{CeO}_{2} \mathrm{NP}$ solutions to be used as described previously for metal oxides ${ }^{16}, 17$.

4. Prepare $0.05 \mu \mathrm{g} / \mathrm{L} \mathrm{CeO}_{2} \mathrm{NP}$ solution for the $\mathrm{PN}$ and $1 \mu \mathrm{g} / \mathrm{L}$ solution for the $\mu \mathrm{DG}$.

1. Weigh $25.6 \mathrm{mg} / \mathrm{mL} \mathrm{CeO} 2 \mathrm{NP}$ in a glass vessel of $15 \mathrm{~mL}-20 \mathrm{~mL}$ total and add $10 \mathrm{~mL}$ of $0.05(\mathrm{v} / \mathrm{v})$ BSA solution prepared in ultrapure water.

2. Use a fingertip sonicator with a power of $7.35 \mathrm{~W}$ to homogenize the particle solution for $309 \mathrm{~s}$.

\section{Instrumental tuning and parameters}

1. Make sure the MDG generator is turned off and connect the dual-inlet sample introduction setup which was built in step 1 with the injector of the ICP-MS instrument with a clamp. Flush the inlet system for $5-10$ min with the nebulizer gas ( $\mathrm{Ar})$ and the droplet transportation gas $(\mathrm{He})$. 
NOTE: The ICP-MS instrument has to be protected against the penetration of high levels of oxygen into the plasma room.

2. Turn off the droplet transportation gas $(\mathrm{He})$ and start the ICP-MS system

3. Tune the instrument in the measurement mode which one wants to utilize using the instrument standard tuning solution that is specified by the manufacturer of the ICPMS system.

NOTE: A standard tuning solution consist of, for example barium, cerium, indium, uranium, bismuth, cobalt, lithium (all $1 \mu \mathrm{g} / \mathrm{L}$ ) in a mixture of $2.5 \%(\mathrm{v} / \mathrm{v})$ nitric acid and $0.5 \%$ (v/v) hydrochloric acid.

4. Determination of the sample uptake rate of the PN.

1. Fill a vessel with $15 \mathrm{~mL}$ of water.

2. Weigh the vessel.
3. Connect the vessel to the tubing of the PN.

4. Start the peristaltic pump by click on the peristaltic pump start button in the instrument software.

5. Start a 5 min timer.

6. Remove the uptake line from the vessel exactly after 5 min. Weigh the vessel again.

7. Calculate the sample uptake rate $(\mathrm{mL} / \mathrm{min})$ using the formula: vessel weight before - vessel weight after / time duration.

5. Optimize instrumental parameters to improve analyte sensitivity if necessary, e.g., nebulizer gas flow rate, sampling depth, plasma power.

NOTE: See Table 2 as an example of instrumental parameters that can be optimized in an ICP-MS system.

6. Adjust the He gas flow until a constant signal rate can be detected as a function of the drop formation rate.

\begin{tabular}{|c|c|}
\hline Parameter & Value \\
\hline \multicolumn{2}{|l|}{ ICP - MS: } \\
\hline Plasma Power (W) & 1600 \\
\hline Sampling Depth (mm) & 4 \\
\hline \multicolumn{2}{|l|}{ Flow rates $\left(\mathrm{L} \mathrm{min}^{-1}\right)$ : } \\
\hline Auxiliary Gas & 0.65 \\
\hline Cooling Gas & 14 \\
\hline \multicolumn{2}{|l|}{ Times (s) } \\
\hline Data acqusition (s) & 1200 \\
\hline Dwell time (s) & 0.01 \\
\hline \multicolumn{2}{|l|}{ Interface: } \\
\hline $\begin{array}{l}\text { PN Sample uptake } \\
\text { rate }\left(\mathrm{mL} \mathrm{min}^{-1}\right)\end{array}$ & 0.21 \\
\hline
\end{tabular}




\begin{tabular}{|c|c|c|c|}
\hline Nebulizer Gas (L min-1) & \multicolumn{3}{|c|}{0.92} \\
\hline \multicolumn{4}{|l|}{$\mu D G:$} \\
\hline Capillary diameter $(\mu \mathrm{m})$ & \multicolumn{3}{|c|}{75} \\
\hline Drop rate $(\mathrm{Hz})$ & \multicolumn{3}{|c|}{10} \\
\hline He makeup gas $\left(\mathrm{L} \min ^{-1}\right)$ & \multicolumn{3}{|c|}{0.27} \\
\hline \multirow[t]{2}{*}{ Operation mode } & \multicolumn{3}{|c|}{ Triple pulse } \\
\hline & Set1 & Set2 & Set3 \\
\hline Voltage (V) & 53 & 51 & 47 \\
\hline Pulse width ( $\mu \mathrm{s})$ & 20 & 25 & 12 \\
\hline Pulse delay ( $\mu \mathrm{s})$ & 4 & 2 & 1 \\
\hline
\end{tabular}

Table 2: Values of instrumental parameters used.

\section{Multi-mode measurement of nanoparticle samples}

1. Prepare the $\mu D G$ control unit

1. Turn on the power supply switch of the $\mu \mathrm{DG}$ control unit.

2. Click Start on the first screen to start up the control unit.

3. Click Global Settings to choose the pulse mode to be used.

4. Click on the right graphical button at pulse mode to choose the triple pulse mode.

NOTE: The settings for the triple pulse mode are given in Table 2.

2. Prepare the $\mu D G$ unit

1. Click On/Off to start the $\mu D G$.
2. Fill the sample vessel with the sample solution to be measured.

3. Connect the sample vessel to the $\mu \mathrm{DG}$ unit.

4. Using a $10 \mathrm{~mL}$ syringe to purge air through the vessel and the $\mu D G$ unit.

5. Connect the syringe to the syringe port on the sample container vessel.

6. Push the syringe plunger until a constant liquid stream is observed coming out the $\mu \mathrm{DG}$ head.

7. Maintain the pressure for $10 \mathrm{~s}$.

8. Remove the syringe.

9. Place the $\mu D G$ unit into the focus zone of the CCD camera to observe the formed droplets.

10. Connect the CCD camera to a PC or laptop.

11. Start the CCD camera software to observe the formed droplets 
12. Click Start to get a live view of the droplets.

13. Observe constant droplet formation.

14. Place the $\mu D G$ head onto the inverted torch on the dual-inlet sample introduction system.

3. Validate both, the $\mu \mathrm{DG}$ unit and the $\mathrm{PN}$ for each element of interest by measuring repeated multi point-calibrations. NOTE: For ICP-MS data acquisition, use the software associated with the instrument.

4. Determine the linear range of the multi-point calibration by importing the experimental data into a spreadsheet software.

1. Calculate the arithmetic mean of each calibration point.

2. Determine the intercept, slope and correlation coefficient.

NOTE: For sp-ICP-MS the correlation coefficient should be $>0.99^{18}$.

5. Choose a concentration within the linear range of the calibration curves for one-point calibrations later on.

6. Following the steps below for measurement and validation (by using reference materials like NIST 8012 , NIST 8013 or NIST 8017 or similar) of the multi-mode nanomaterial quantification (Figure 2).

1. Select a nanoparticle and an ionic standard according to the analyte of interest.

2. Prepare the $\mu \mathrm{DG}$ unit according to 5.2 with an ionic standard solution.
3. Add a diluted acid solution (e.g., $0.5 \% \mathrm{v} / \mathrm{v} \mathrm{HCl}$ ) via the PN.

4. Start the measurement of the ICP-MS system in time resolved mode.

5. Click On/Off after $120 \mathrm{~s}$ to stop the $\mu \mathrm{DG}$ and exchange the dilute acid solution at the PN with the ionic standard.

6. After $330 \mathrm{~s}$ once again exchange the ionic standard at the PN with a dilute acid solution.

7. Meanwhile remove the $\mu D G$ unit from the setup.

8. Exchange the sample vessel (glass vial) of the $\mu \mathrm{DG}$ unit with a vessel containing a diluted acid solution (e.g., 3.5\% $\mathrm{HNO}_{3}$ ) in order to clean the $\mu \mathrm{DG}$ unit.

1. Fill a $10 \mathrm{~mL}$ syringe with air.

2. Connect the syringe to the injection port of the $\mu D G$ unit and empty the syringe until a jet of liquid appears from the $\mu \mathrm{DG}$ head and maintain pressure for $30 \mathrm{~s}$.

3. Prepare the $\mu \mathrm{DG}$ as specified in step 5.2 with the NP sample and attach the $\mu D G$ unit back to the setup at $510 \mathrm{~s}$.

9. Click On/Off after $810 s$ to stop the $\mu D G$.

10. Exchange the dilute acid solution at the PN with the NP sample and measure for another $300 \mathrm{~s}$.

11. Stop the measurement after approx. 1,200 s.

12. Clean the $\mu \mathrm{DG}$ unit as specified in step 5.5.8. 


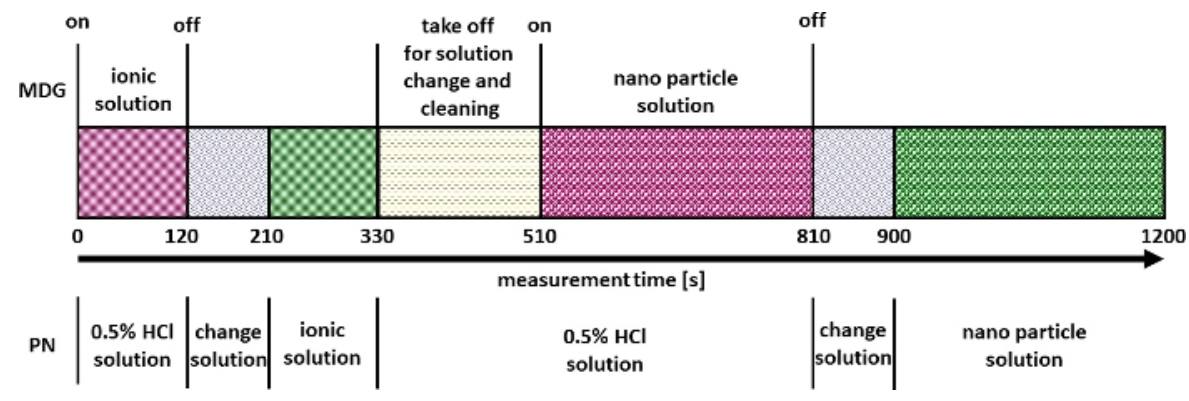

Figure 2: Measurement strategy for multi-mode nanomaterial quantification. Please click here to view a larger version of this figure.

\section{Data analysis}

NOTE: To simplify all calculation steps, a corresponding spreadsheet was prepared (see Supplementary File).

1. Use a spreadsheet or software which can handle data frames to process the data and import the measured data. Paste the intensity values of the entire measurement in the spreadsheet software (included in the electronic supplement) in column $A$, the data will be visualized. Enter all necessary experimental parameters for calculation into the table "Input Parameter".

2. Define the regions of interest (ROI) for $\mu D G$ ionic (I), PN ionic (II), $\mu D G$ NP (III) and PN NP (IV) by selecting the appropriate spreadsheet cells. Using the graph in the prepared sheet to define the boundaries of the ROls and enter the values into the "Determination of the Region of Interest" table (cells C1:E7).

3. Copy and paste the each data set in a separate column. Press the button Copy ROI in the prepared sheet to split the measurement into the four ROls (column M:P).
4. Calculate the arithmetic mean of I and II.

5. Apply the iterative approach to separate particle or droplet signals and background for III and IV.

1. Calculate the arithmetic mean and standard deviation of all measured values.

2. Calculate a limit or cut-off value by mean value + $5^{*}$ standard deviation.

3. Remove all signals smaller than the limit value of III and IV by using the Cut command on the identified particle signals. Use Paste to paste them in a separate column.

4. Repeat steps 1-3 until the mean value and standard deviation are constant.

NOTE: In columns $Q$ to $B D$ of the prepared sheet, the iterative approach to separate background and particle signals is performed five times.

6. Calculate the arithmetic mean of the identified particle signals of III and IV.

7. Calculate the minimum detectable particle size (LOD size - nm) for $\mu \mathrm{DG}$ NP and PN NP by using the instrumental 
limit of detection of the analyte (LOD - counts), the analyte sensitivity $\left(\mathrm{S}_{\mathrm{C}}\right.$,ionic - counts/( $\left.\left.\mu \mathrm{g} / \mathrm{L}\right)\right)$, the sample uptake rate $\left(q_{s}-\mathrm{mL} / \mathrm{min}\right)$, the transport efficiency $(\eta-$ relative unit) and the bulk material density $\left(\rho-\mathrm{g} / \mathrm{cm}^{3}\right)$ :

1. $L O D($ counts $)=I_{\text {Background }}+5 * \sigma_{\text {Background }}$

2. $L_{O D D_{\text {size }}}(\mathrm{nm})=\sqrt[3]{\left(6 *\left(\frac{L O D}{s_{\text {C,ionic }}}\right) *\left(\frac{q_{s}}{60}\right) * \eta\right) /(\pi * \rho)}$

8. Calculate the mass $\left(m_{a}, p\right)$ and particle size $(d-n m$, assuming the particles are spherical) of identified particle signals for $\mu \mathrm{DG} N \mathrm{NP}$ and $\mathrm{PN} N \mathrm{~N}$ according to the three analysis modes applied by taking the ionic metal concentration of a standard solution $\left(\mathrm{c}_{\mathrm{a}}-\mu \mathrm{g} / \mathrm{L}\right)$ and the ion flux in the plasma (counts/s) into account:

1. Mass: $m_{a, p}(f g)=\left(\frac{q_{s} * \eta * c_{a}}{q_{i, a}}\right) n_{i, p} * 10^{-6}$

2.

Size: $d(n m)=\sqrt[3]{\frac{\left(6 * m_{a p p}\right)}{(\pi * \rho)}}$

9. Calculate the specific transport efficiency of the analysis modes by using the number of particles detected ( $q p$ ), the particle concentration of the sample ( $c_{p}$, used $\left.-1 / \mathrm{mL}\right)$, the analyte sensitivity of the PN and MDG $\left(S_{m}\right.$,ionic,PN,

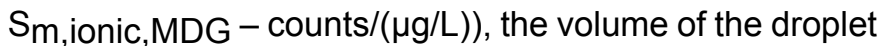
$\left(V_{d r o p}-p L\right)$, the dwell time $\left(t_{d}-m s\right)$, the transport efficiency of the PN (nPN), the transport efficiency of the $\mu D G\left(\eta_{\mu D G}\right)$, the intensity of the ionic solutions measured by the $\mathrm{PN}$ and $\mu \mathrm{DG}$ ( Iionc, $\mathrm{PN}$, lionic, $\mu \mathrm{DG}$ - counts) and the concentration of the ionic solution used for both injection systems (Cionic,PN, Cionic, $\mu D G-\mu g / L$ ):
1. Mode

$$
\eta_{P N}=\frac{q_{p}}{c_{p, u s e d} q_{s}}
$$

2. Mode

$$
\eta_{P N}=\frac{s_{\text {mionic, } P N}}{s_{\text {mionic, }, M D G}}=\left(\frac{s_{\text {C,ionic }, P N}}{s_{C, \text { ionic }, M D G}}\right) *\left(\frac{V_{\text {Drop }}}{q_{s} * t_{d}}\right)
$$

3. $S_{\text {m,ionic, } P N}\left(\right.$ counts $\left.n g^{-1}\right)=\frac{s_{C, i o n i c, P N}}{q_{s^{*} t_{d^{*}} \eta_{P N}}}$

4. $S_{\text {m,ionic, } \mu D G}\left(\right.$ counts $\left.n g^{-1}\right)=\frac{s_{\text {C,ionic } \mu D G}}{V_{D \text { Drop }} * \eta_{\mu D G}}$

5. $S_{c, \text { ionic }, P N}\left(\right.$ counts $\left.\left(n g m L^{-1}\right)^{-1}\right)=\frac{I_{\text {ionic }, P N}}{c_{\text {ionic } P N}}$

6. $S_{c, \text { ionic }, \mu D G}\left(\right.$ counts $\left.\left(n g m L^{-1}\right)^{-1}\right)=\frac{I_{\text {ionic } \mu D G}}{c_{\text {ionic } \mu D G}}$

10. Assume that the transport efficiency of $\mu D G$ is equal to $1: 19$

1. $\eta_{\mu D G}=1$

11. Calculate the particle number concentration of the NP solution analyzied by taking into account the injected sample volume during the measurement $\left(\mathrm{V}_{\text {injected }}\right)$ :

$c_{p, \text { detected }}\left(\# \boldsymbol{m} \boldsymbol{L}^{-1}\right)=\frac{q_{p}}{\eta} * \frac{1}{V_{\text {injected }}}$

NOTE: In the prepared sheet all calculations are performed automatically after the splitting. The results are shown in table "Output Parameters" (cells BH7:BR35) and contains the formulas described above including individual calculation steps.

\section{Representative Results}




\section{A}
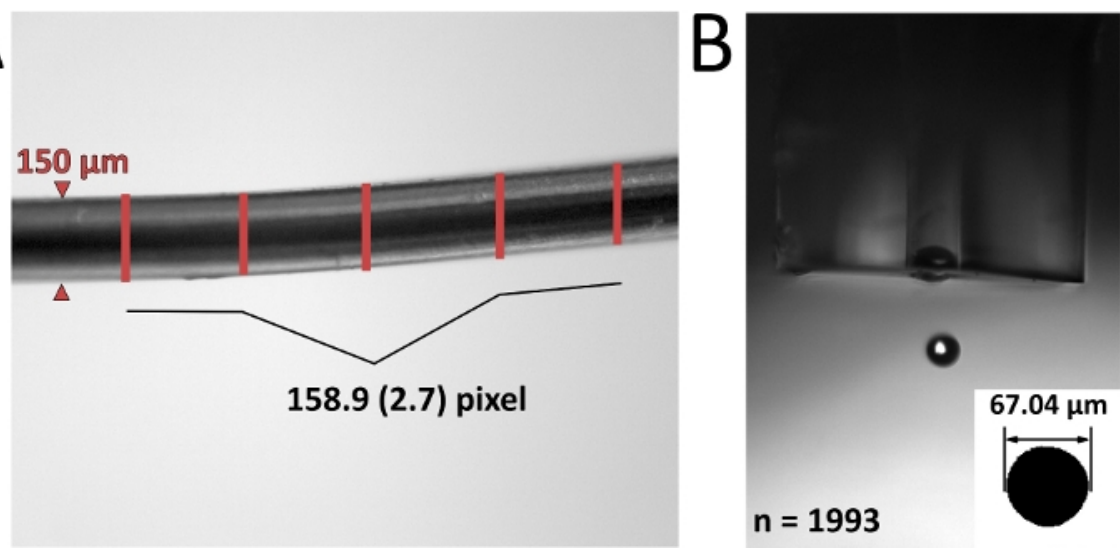

Figure 3: Determination of the droplet size with the CCD-camera. Calibration of the CCD-camera with a $150 \mu \mathrm{m}$ copper wire (A) and determination of the droplet size after converting the achieved droplet pictures into a binary color picture (B). Please click here to view a larger version of this figure.
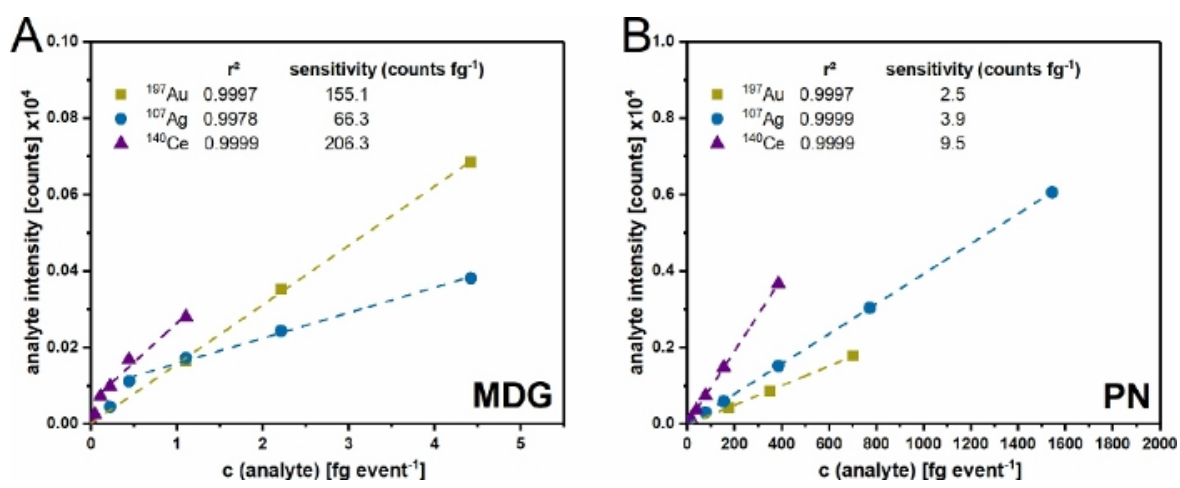

Figure 4: Validation of the dual inlet-setup. Multi-point calibration of the $\mu \mathrm{DG}(\mathbf{A})$ and $P N(\mathbf{B})$ inlet system for gold (Au), silver $(\mathrm{Ag})$ and cerium (Ce). The used concentration in the range of $0.2-20 \mu \mathrm{gL} \mathrm{m}^{-1}$ is converted, depending on used experimental conditions in mass per detected event. The presented data are the average values of three independent replicates. Please click here to view a larger version of this figure. 


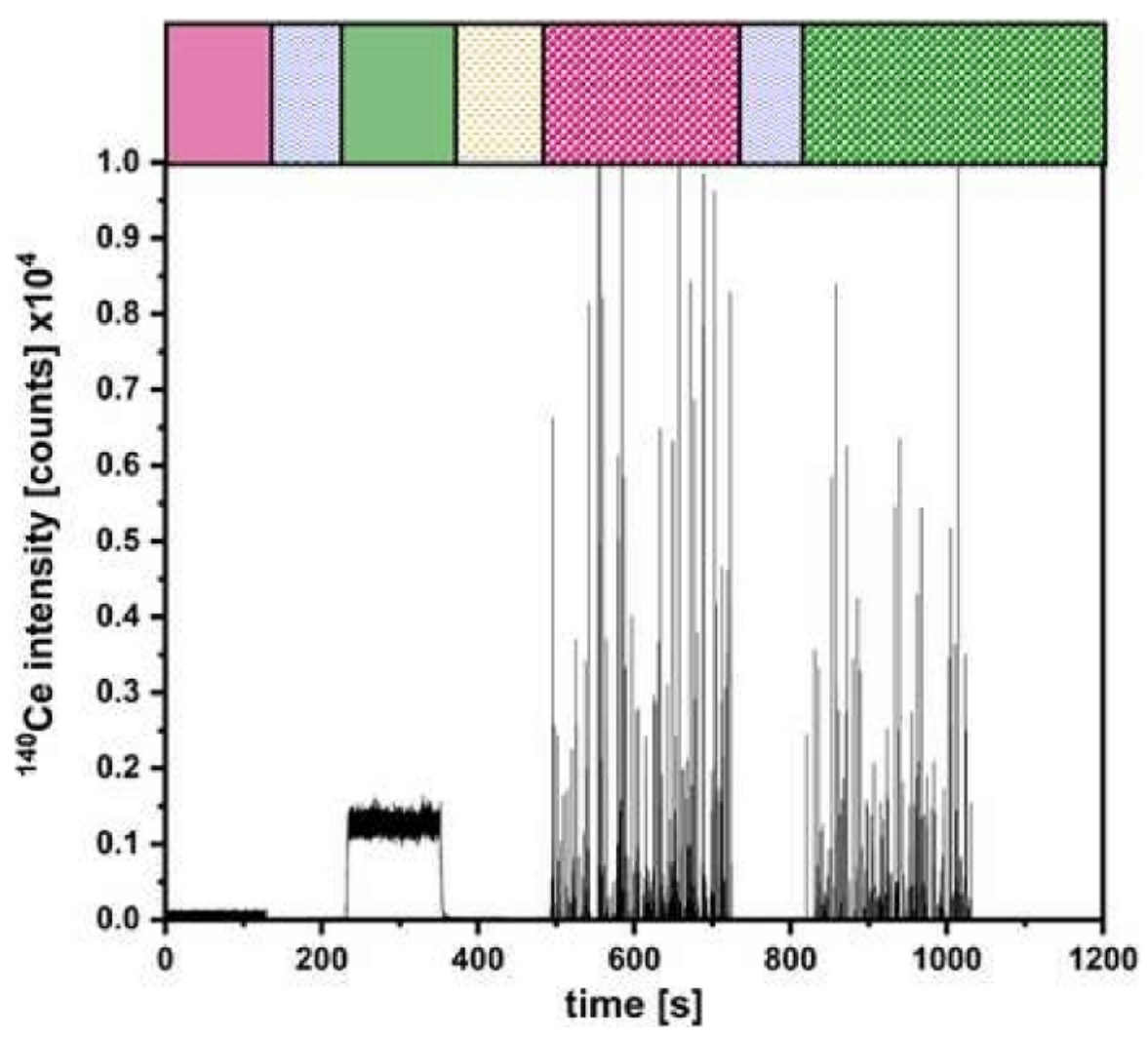

Figure 5: Representing measurement for the dual-inlet setup. The quantification of $\mathrm{CeO}_{2} \mathrm{NP}$ with colored bars as done in Figure 2 for the different injection steps. Please click here to view a larger version of this figure. 


\begin{tabular}{|c|c|c|c|c|c|c|c|c|}
\hline \multirow[t]{2}{*}{ Sample } & $\begin{array}{l}\text { Analysis } \\
\text { Mode / }\end{array}$ & \multirow{2}{*}{$\begin{array}{c}\text { Inlet } \\
\text { for NP } \\
\text { sample }\end{array}$} & \multirow{2}{*}{$\begin{array}{c}\text { Inlet for } \\
\text { calibration } \\
\text { standards }\end{array}$} & $\eta$ & $m_{a}, p$ & $\begin{array}{l}\text { NP size } \\
\text { (d) }\end{array}$ & \#NPs & \multirow[t]{2}{*}{$\begin{array}{c}\text { Recovery } \\
\text { (\%) }\end{array}$} \\
\hline & $\begin{array}{c}\eta P N \\
\text { etermination }\end{array}$ & & & $(\%)$ & $(f g)$ & $(\mathrm{nm})$ & $\left(\mathrm{mL}^{-1} \times 10^{3}\right)$ & \\
\hline Au $56 \mathrm{~nm}$ & Mode-I / & \multirow[t]{2}{*}{ PN } & \multirow{2}{*}{\begin{tabular}{|c|} 
PN: Au \\
ionic \& \\
AuNP \\
standards
\end{tabular}} & \multirow[t]{2}{*}{$1.8(0.1)$} & \multirow[t]{2}{*}{$1.9(0.5)$} & \multirow[t]{2}{*}{$57.2(4.3)$} & \multirow[t]{2}{*}{$28.1(0)$} & \multirow[t]{2}{*}{100} \\
\hline NIST 8013 & $\begin{array}{l}\text { Counting } \\
\text { Method }\end{array}$ & & & & & & & \\
\hline & Mode-II / & \multirow[t]{2}{*}{ PN } & 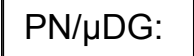 & \multirow[t]{2}{*}{$1.9(0.1)$} & \multirow[t]{2}{*}{$2(0.4)$} & \multirow[t]{2}{*}{$58(3.6)$} & \multirow[t]{2}{*}{$25.6(1.6)$} & \multirow[t]{2}{*}{91} \\
\hline & $\begin{array}{c}\text { Sensitivity } \\
\text { Ratio }\end{array}$ & & $\begin{array}{l}\text { Au ionic } \\
\text { standards }\end{array}$ & & & & & \\
\hline & Mode-III / & \multirow[t]{2}{*}{$\mu \mathrm{DG}$} & $\mu D G:$ & \multirow[t]{2}{*}{100} & \multirow[t]{2}{*}{$1.7(0.2)$} & \multirow[t]{2}{*}{$55(2.4)$} & \multirow[t]{2}{*}{$394.4(29.3)$} & \multirow[t]{2}{*}{70} \\
\hline & $\eta_{\mu D G}=1$ & & $\begin{array}{l}\text { Au ionic } \\
\text { standard }\end{array}$ & & & & & \\
\hline \multicolumn{5}{|c|}{ Expected size (nm) } & & $56.0(0.5)$ & & \\
\hline $\mathrm{Ag} 75 \mathrm{~nm}$ & Mode-I / & \multirow[t]{2}{*}{ PN } & \multirow{2}{*}{\begin{tabular}{|c|} 
PN: Ag \\
ionic \& \\
AgNP \\
standards
\end{tabular}} & \multirow[t]{2}{*}{$2.3(0.2)$} & \multirow[t]{2}{*}{$1.9(0.2)$} & \multirow[t]{2}{*}{$70.2(2.3)$} & \multirow[t]{2}{*}{$21.6(0)$} & \multirow[t]{2}{*}{100} \\
\hline NIST 8017 & $\begin{array}{l}\text { Counting } \\
\text { Method }\end{array}$ & & & & & & & \\
\hline & Mode-II / & \multirow[t]{2}{*}{ PN } & 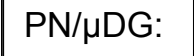 & \multirow[t]{2}{*}{$2.5(0.2)$} & \multirow[t]{2}{*}{$2(0.2)$} & \multirow[t]{2}{*}{$71.5(2.1)$} & $20.5(1.9)$ & 95 \\
\hline & $\begin{array}{c}\text { Sensitivity } \\
\text { Ratio }\end{array}$ & & $\begin{array}{l}\text { Ag ionic } \\
\text { standards }\end{array}$ & & & & & \\
\hline & Mode-III / & $\mu \mathrm{DG}$ & $\mu \mathrm{DG}:$ & 100 & $2.5(0.2)$ & $76.7(2.3)$ & $757.1(68.7)$ & 88 \\
\hline & $\eta_{\mu D G}=1$ & & $\begin{array}{l}\text { Ag ionic } \\
\text { standard }\end{array}$ & & & & & \\
\hline & Expe & cted size & $\mathrm{nm})$ & & & $74.6(3.8)$ & & \\
\hline $\begin{array}{c}\mathrm{CeO}_{2} \mathrm{JRC} \\
\mathrm{NM} 212\end{array}$ & Mode-I / & PN & $\begin{array}{l}\text { PN: Ce } \\
\text { ionic \& }\end{array}$ & $1.7(0)$ & $0.90(0.09)$ & $61.9(2.0)$ & $7.59(0.32)$ & - \\
\hline $10-100 \mathrm{~nm}$ & $\begin{array}{l}\text { Counting } \\
\text { Method }\end{array}$ & & $\begin{array}{c}\text { AuNP } \\
\text { standards }\end{array}$ & & & & & \\
\hline
\end{tabular}




\begin{tabular}{|c|c|c|c|c|c|c|c|}
\hline Mode-II / & \multirow[t]{2}{*}{ PN } & 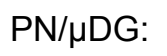 & \multirow[t]{2}{*}{$4.9(1.4)$} & \multirow[t]{2}{*}{$1.36(0.35)$} & \multirow[t]{2}{*}{$70.6(5.9)$} & \multirow[t]{2}{*}{$5.42(1.7)$} & \multirow[t]{2}{*}{ - } \\
\hline $\begin{array}{c}\text { Sensitivity } \\
\text { Ratio }\end{array}$ & & $\begin{array}{l}\text { Ce ionic } \\
\text { standards }\end{array}$ & & & & & \\
\hline Mode-III / & \multirow[t]{2}{*}{$\mu \mathrm{DG}$} & $\mu \mathrm{DG}:$ & \multirow[t]{2}{*}{100} & \multirow[t]{2}{*}{$1.63(0.62)$} & \multirow[t]{2}{*}{$74.4(9.2)$} & \multirow[t]{2}{*}{590 (168) } & \multirow[t]{2}{*}{-} \\
\hline$\eta_{\mu D G}=1$ & & $\begin{array}{l}\text { Ce ionic } \\
\text { standard }\end{array}$ & & & & & \\
\hline
\end{tabular}

Table 3: Results of the dual-inlet setup. Transport efficiency, metal mass fraction, diameter and NP number concentration for Au NIST 8013, Ag NIST 8017 and $\mathrm{CeO}_{2}$ JRC NM 212 (n=3) NP materials using three analysis modes and three transport efficiency determination methods. The \% recovery is defined as the ratio of the determined \#NPs to the expected \#NPs. The table is reprinted with permission from reference ${ }^{14}$.

The protocol presented here allows for the determination of the particle mass and number concentration. The $\mu \mathrm{DG}$ droplet formation, including the droplet size (Figure 3) was characterized beforehand (Table 3).

After the setup was assembled (Figure 1) and the droplet size determined, both injection systems were validated with ionic standards (Figure 4). An accuracy of $r^{2}>0.99$ could be achieved with both injection systems for all investigated elements. However, there are differences in both systems due to the amount of analyte introduced and transported. Since the $\mu D G$ has a very high transport efficiency (up to $100 \%)$, higher analyte sensitivities compared to the PN are observed with low mass input at the same time. However, the measured concentrations introduced by the $\mu D G$ have to be separated into two linear ranges. For Ag, the first linear range can be observed between 0 and $0.5 \mathrm{fg} \mathrm{event}^{-1}$ and the second between 0.5 and fg event ${ }^{-1}$. In contrast, the first linear range for $\mathrm{Ce}$ is between 0 and $0.25 \mathrm{fg}$ event $^{-1}$ and the second between 0.25 and $3 \mathrm{fg} \mathrm{event}^{-1}$. The linear range for $\mathrm{PN}$ for the measured concentrations appears to be higher. This is most likely related to the difference of introduced mass into the ICP-MS per detection event. The $\mu \mathrm{DG}$ injects a constant absolute quantity in a low volume per drop and detection event resulting in lower detected mass compared to the introduction of samples with the PN.

After the successful validation, experiments can be performed as described in Figure 2. A result of such experiments is exemplified in Figure $\mathbf{5}$ for the determination of the particle size and number concentration of $\mathrm{CeO}_{2} \mathrm{NP}$. Here the signals for the introduced ionic and NP solutions via $\mu D G$ and $P N$ can be identified. A triple determination was carried out for all investigated particles.

The evaluation of the obtained data was performed as described above and is summarized in Table 3 . For the $\mathrm{Au}$ and $\mathrm{Ag}$ NP used for validation of the duel-inlet setup and the three analysis modes, the certified particle size and number concentration could be achieved with all analysis modes performed. The mean particle sizes obtained for $\mathrm{CeO}_{2}$ are between 10 and $100 \mathrm{~nm}$, the range specified by the manufacturer. 

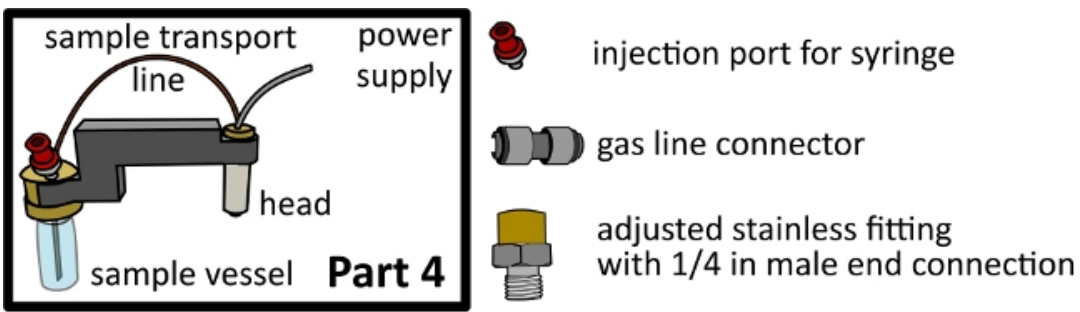

micro droplet generation unit
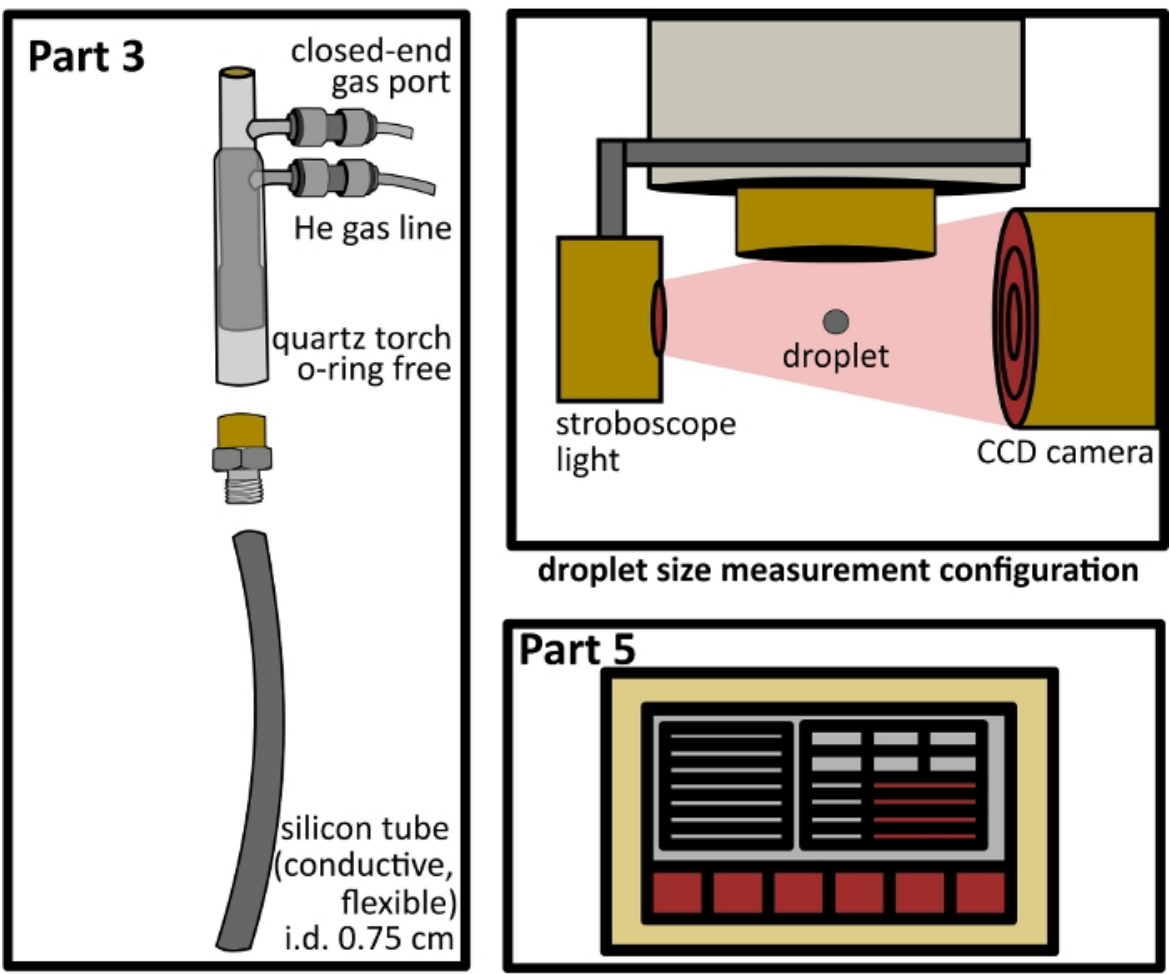

droplet size measurement configuration

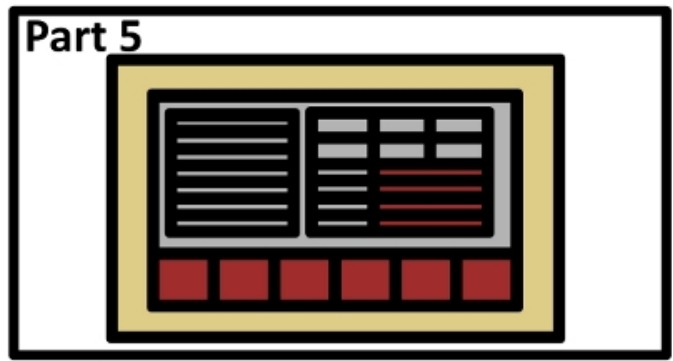

micro droplet transport unit

micro droplet generator control unit
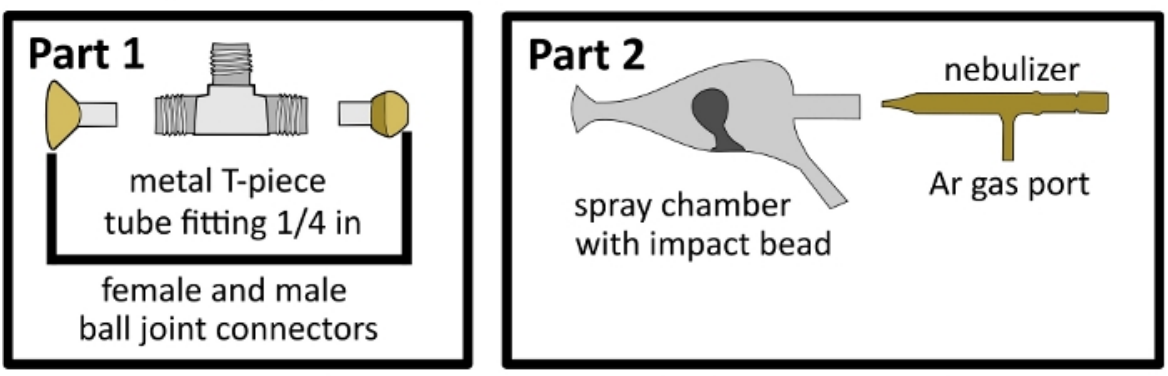

connector unit

conventional sample introduction system

Figure 1: Design of the dual-inlet interface setup. Part 1 - connector unit, Part 2- conventional introduction system, Part 3 - microdroplet transport unit, Part 4- microdroplet generation unit, Part 5- microdroplet control unit, and open configuration for droplet size measurement including a stroboscope light and a CCD camera. Please click here to view a larger version of this figure. 


\section{Discussion}

The aim of the developed dual-inlet setup is the characterization and quantification of NP as accurately as possible concerning their size and number concentration by using different analysis modes, independent of the analyte to be investigated. By combining a low volume $(\mathrm{pL})$ and high mass transport (up to $100 \%$ ) introduction system ( $\mu D G$ ) with a conventional introduction system (PN) this is achievable. By using the setup presented in this work, the elementspecific based transport efficiency required for quantification of particle mass can be determined based on ionic standards and independently of NP reference materials. In addition, the NPs introduced into the ICP-MS with the $\mu \mathrm{DG}$ have a narrower (AuNP) or similar (AgNP) particle size distribution. Otherwise, for $\mathrm{CeO}_{2}$ a broader size distribution for the $\mu D G$ was observed and can be attributed to the higher polydispersity of the analyzed sample. Due to the introduction of low volume two NPs can be detected separately from each other, which would otherwise be interpreted as one NP in the conventional setup ${ }^{14}$.

The advantages resulting from the $\mu \mathrm{DG}$ transport unit are the high degree of flexibility due to the flexible silicon tubing, which simplifies the alignment of the setup. The torch with the injector can also be adjusted during the setup while still connected to the ICP-MS. The additional applied He gas flow prevents a collision of the droplets formed by the $\mu D G$ head with the tubing walls ${ }^{20}$. Furthermore, the $\mathrm{He}$ gas allows for the removal of $\mu \mathrm{DG}$ head during the sample exchange even when ICP-MS is still operating. Keeping the ICP in an operational state is crucial for stable and robust measurement. Since the $\mu D G$ head must be cleaned and rinsed with every new sample or standard, the He flow is vital for the operation of the inlet system introduced in this work. Furthermore, all parts of the dual-inlet setup have to be correctly connected in order to prevent the penetration of oxygen into the system. In order to diminish oxygen in the presented setup, the system is flushed with the nebulizer and droplet transportation gas before the ignition of the plasma for at least 5 to $10 \mathrm{~min}$.

When the formed droplets reach the connector unit, they are transported into the plasma by a nebulized liquid stream, also referred to as a wet-plasma condition. Compared to the use of dry plasma conditions this leads to an increased liquid content of the plasma. Consequently, the signal intensity decreases as well as fluctuation of the signal increase, i.e., a higher standard deviation of the mean measurement signal ${ }^{13}$. However, by using the $\mu \mathrm{DG}$ and concentrations in the range of $0.2 \mu \mathrm{g} / \mathrm{L}$ signals above the background can be detected. The corresponding injected mass per droplet has low metal content, which is close to the detection limits for some elements (i.e., $\mathrm{Au}, \mathrm{Ag}, \mathrm{Ce}$ ). If different concentrations for calibration along this limit are used two linear regions can be observed with an overlap at approximately 0.05 $\mu \mathrm{g} / \mathrm{L}$ for $\mathrm{Ce}$ and $2 \mu \mathrm{g} / \mathrm{L}$ for Ag. Below the overlapping region the observed signals are close to the element specific background ${ }^{21}$. Above these limit the linear working range of the $\mu \mathrm{DG}$ can be identified. Even with the ability to measure low concentrations, it is impossible to distinguish between ions and NP of the same analyte within a droplet if they are simultaneously present. Otherwise, by using the conventional introduction system the average ionic background can be determined and subtracted from all signals to get the particle signals only.

MDG based system also have several limitations which can be partially circumvented by the application of proposed dual inlet system. However, if the droplet frequency of $\mu D G$ exceeds $50 \mathrm{~Hz}$ it is not possible to create a consistent droplet 
pattern. The formed droplets might collide and, therefore, exchange of analyte occurs. The correct adjustment of gas flow rates is also important for a reliable transport of the droplet into the ICP-MS system as well as for correct operation of the PN. The proposed dual inlet system currently does not support automation of the measurement procedure as there is a requirement of manually changing the sample solutions.

In future, $\mu \mathrm{DG}$ can be used for characterizing and quantifying NPs in complex matrices and environmental samples. To prevent clogging of $\mu \mathrm{DG}$ because of the higher solution viscosity, complexity, and surface tension, an appropriate head design should be used. Depending on the $\mu \mathrm{DG}$ head design and operation of the power supply, it might be possible to generate droplets that contain particle-like systems such as cells, micelles, or lipid carriers for which standard reference materials are not available at all.

\section{Disclosures}

All authors declare no conflict of interest.

\section{Acknowledgments}

This work was supported by BfR SFP 1322-642 for F.L.K and P.R., BfR SFP 1322-724 for D.R. and BfR senior scientist fellowship for S.A.P.

\section{References}

1. Linsinger, T. P. J., Peters, R., Weigel, S. International interlaboratory study for sizing and quantification of Ag nanoparticles in food simulants by single-particle ICPMS. Analytical and Bioanalytical Chemistry. 406 (16), 3835-3843 (2014).
2. Krystek, P. et al. Method development and interlaboratory comparison about the determination of titanium from titanium dioxide nanoparticles in tissues by inductively coupled plasma mass spectrometry. Analytical and Bioanalytical Chemistry. 406 (16), 3853-3861 (2014).

3. Degueldre, C., Favarger, P. Y., Bitea, C. Zirconia colloid analysis by single particle inductively coupled plasmamass spectrometry. Analytica Chimica Acta. 518 (1-2), 137-142 (2004).

4. Degueldre, C., Favarger, P. Y. Colloid analysis by single particle inductively coupled plasma-mass spectroscopy: a feasibility study. Colloid Surface A. 217 (1-3), 137-142 (2003).

5. Pace, H. E. et al. Determining transport efficiency for the purpose of counting and sizing nanoparticles via single particle inductively coupled plasma mass spectrometry. Analytical Chemistry. 83 (24), 9361-9369 (2011).

6. Verboket, P. E., Borovinskaya, O., Meyer, N., Gunther, D., Dittrich, P. S. A new microfluidics-based droplet dispenser for ICPMS. Analytical Chemistry. 86 (12), 6012-6018 (2014).

7. Shigeta, K. et al. Application of a micro-droplet generator for an ICP-sector field mass spectrometer - optimization and analytical characterization. Journal of Analytical Atomic Spectrometry. 28 (5), 646-656 (2013).

8. Gschwind, S., Hagendorfer, H., Frick, D. A., Gunther, D. Mass quantification of nanoparticles by single droplet calibration using inductively coupled plasma mass spectrometry. Analytical Chemistry. 85 (12), 5875-5883 (2013).

9. Gschwind, S. et al. Capabilities of inductively coupled plasma mass spectrometry for the detection of 
nanoparticles carried by monodisperse microdroplets. Journal of Analytical Atomic Spectrometry. 26 (6), 1166-1174 (2011).

10. F. Zarrln, S. L. K., J. R. Socha. Droplet size measurements of various nebulizers using differential electrical mobluty particle sizer. Journal of Aerosol Science. 22, 343-346 (1991).

11. Geertsen, V., Lemaitre, P., Tabarant, M., Chartier, F. Influence of design and operating parameters of pneumatic concentric nebulizer on micro-flow aerosol characteristics and ICP-MS analytical performances. Journal of Analytical Atomic Spectrometry. 27 (1), 146-158 (2012).

12. Mehrabi, K., Günther, D., Gundlach-Graham, A. Single-particle ICP-TOFMS with online microdroplet calibration for the simultaneous quantification of diverse nanoparticles in complex matrices. Environmental Science. Nano. 6, 3349-3358 (2019).

13. Ramkorun-Schmidt, B., Pergantis, S. A., EstebanFernandez, D., Jakubowski, N., Gunther, D. Investigation of a combined microdroplet generator and pneumatic nebulization system for quantitative determination of metal-containing nanoparticles using ICPMS. Analytical Chemistry. 87 (17), 8687-8694 (2015).

14. Rosenkranz, D. et al. Improved validation for single particle ICP-MS analysis using a pneumatic nebulizer/ microdroplet generator sample introduction system for multi-mode nanoparticle determination. Analytica Chimica Acta. 1099, 16-25 (2020).

15. Report of investigation reference material. National Institute of Standards and Technology. Reference material 8017 (2015).
16. Tavares, A. M. et al. Genotoxicity evaluation of nanosized titanium dioxide, synthetic amorphous silica and multiwalled carbon nanotubes in human lymphocytes. Toxicology In Vitro. 28 (1), 60-69 (2014).

17. Au - Kaur, I. et al. Dispersion of Nanomaterials in Aqueous Media: Towards Protocol Optimization. Journal of Visualized Experiments. (130), e56074 (2017).

18. ISO/TS19590 Nanotechnologies. - Size distribution and concentration of inorganic nanoparticles in aqueous media via single particle inductively coupled plasma mass spectrometry. (2017).

19. Shigeta, K. et al. Application of a micro-droplet generator for an ICP-sector field mass spectrometer - optimization and analytical characterization. Journal of Analytical Atomic Spectrometry. 28, 646-656 (2013).

20. Koch, J. et al. Accelerated evaporation of microdroplets at ambient conditions for the on-line analysis of nanoparticles by inductively-coupled plasma mass spectrometry. Journal of Analytical Atomic Spectrometry. 28 (11), 1707-1717 (2013)

21. Tuoriniemi, J., Cornelis, G., Hassellov, M. A new peak recognition algorithm for detection of ultra-small nano-particles by single particle ICP-MS using rapid time resolved data acquisition on a sector-field mass spectrom.eter. Journal of Analytical Atomic Spectrometry. 30 (8), 1723-1729 (2015). 